\title{
Rate of Recurrence After Isolated Coarctation Repair: A Retrospective Study in a Single Tertiary Centre
}

\author{
Sami M AlAhmari ${ }^{*}$, Khalid S Alnajashi ${ }^{1}$, Ahmed Elway ${ }^{2}$, Howida \\ Alqethamy $^{2}$, Turki AlQahtani ${ }^{1}$ and Merna M Atiyah ${ }^{\mathbf{1}}$ \\ ${ }^{1}$ Department of Pediatric Cardiology, PSCC, Riyadh, Kingdom of Saudi Arabia \\ ${ }^{2}$ Department of Pediatric Cardiac Surgery, PSCC, Riyadh, Kingdom of Saudi Arabia \\ *Corresponding Author: Sami M AlAhmari, Department of Pediatric Cardiology, \\ Riyadh, Kingdom of Saudi Arabia.
}

Received: June 22, 2020

Published: July 09, 2020

(C) All rights are reserved by Sami M

AlAhmari., et al.

\begin{abstract}
Objectives: To retrospectively determine the incidence of recoarctation within two years of repair of isolated coarctation of the aorta in patients aged less than 14 years and operated on in our institution, and to identify the risk factors for recoarctation in our study cohort.

Methods: Review of hospital records from 1990-2016 yielded 350 patients aged less than 14 years who had undergone repair of coarctation of the aorta, 84 of whom had isolated coarctation and comprised the study cohort. We studied possible factors influencing the risk of recoarctation, including sex, delivered term or preterm, age group at diagnosis (neonate, infant, child), administration of prostaglandin E1, type of aortic valve (bicuspid, tricuspid), type of coarctation (juxtaductal, preductal, postductal), surgical approach and type of surgical procedure (end-to-end anastomosis, extended end-to-end anastomosis, subclavian flap). We use binary logistic regression to analyse associations between the above-listed patient characteristics and identify independent predictors of recoarctation requiring intervention.

Results: Reintervention by catheterisation was required within two years of surgery by 23 (27.4\%) of the 84 patients with isolated coarctation, 11 of whom (47.8\%) had developed recoarctation within one year of surgery. Binary logistic regression of the examined variables between those who did and did not develop recoarctation failed to identify any significant risk factors for recoarctation $(\chi 2$ (8) $=6.532, \mathrm{p}=0.558)$.

Conclusion: In our cohort, the incidence of recoarctation within two years of repair of isolated coarctation of the aorta in patients aged less than 14 years is $27.4 \%$. We were unable to identify any risk factors for recoarctation.
\end{abstract}

Keywords: Coarctation of Aorta (COA); Prostaglandin E1 (PGE1)

\section{Introduction}

Coarctation of the aorta was first successfully repaired by Crafoord in 1944 [1]. Coarctation of the aorta (CoA) accounts for 5 - 8\% of congenital heart disease [2] and there are multiple different surgical procedures described for coarctation, all of which have their individual advantages and disadvantages. Resection and end-to-end anastomosis-first developed by Gross., et al. [3]-is still widely used especially in older children and adults. Prosthetic patch aortoplasty-first used by Vosschulte [4] in 1957-entails the use of a prosthetic patch to enlarge the site of coarctation. Subcla- vian flap angioplasty-also known as the Waldhausen [5] procedure after its author-involves transection of the subclavian artery and its subsequent use as a flap to enlarge the site of coarctation. Extended resection and end-to-end anastomosis was first described by Amato., et al. [6] in 1977. To the best of our knowledge, this paper is the first to report isolated CoA repair in the Kingdom of Saudi Arabia (KSA). Coarctation repair operative mortality is almost exclusively secondary to associated cardiac anomalies; however, recoarctation continues to be a problem. Recoarctation has been reported in a number of children in surgical series under different techniques 
$[7,8]$. However, in the modern era, recurrent aortic arch obstruction remains a major cause of morbidity following surgical neonatal repair of CoA and re-intervention occurs in 4-20\% of patients [9-11]. Close follow up with clinical blood pressure differences between upper lower extremities using non-invasive diagnostic methods (Doppler echocardiography, magnetic resonance imaging, computed tomography scan, ECG,) was helpful to diagnose recoarctation. There is no consistence finding in previous studies to highlight a specific diagnostic tool and previous data regarding risk factors for recoarctation in KSA are not available.

\section{Methods}

Using an electronic and paper archive database, we reviewed retrospectively all consecutive patients who underwent CoA repair by paediatric cardiac surgeons with multiple teams for a total of 350 patients under 14 years of age at our institution between 1990 and 2016. We included all patients with an isolated CoA (84 patients) and all who had re-intervention by catheterisation (23 patients). Patients with other congenital heart diseases were excluded. Demographic data included sex, weight, preterm/term, age at diagnosis, prostaglandin infusion, time of re-intervention, type of re-intervention, follow-up cardiac CT and MRI, follow-up ECG and ECHO. Anatomical descriptions of the aortic valve and aortic arch were analysed from echocardiographic records and surgical records, respectively. The presence of patency of the arterial duct was also observed.

\section{Inclusion criteria}

Under 14-years-old (within paediatric age group, Ministry of Health, KSA) and received isolated coarctation repair.

\section{Exclusion criteria}

Complex left-sided cardiac lesions, interrupted aortic arch, and ventricular septal defect were excluded from our research because cofactors for coarctation and surgery can be at multiple stages. We excluded other associated lesions to isolate patient non-cardiac lesions as syndromes and for other congenital heart lesions, like Shone complex.

\section{Statistical analysis}

The descriptive analysis of categorical variables is expressed as frequency and percentages. If normally distributed, then continuous variables are displayed as mean \pm standard deviation; if nonnormally distributed, then median with interquartile range $\left(25^{\text {th }}\right.$ and $75^{\text {th }}$ percentiles). Normality distribution was assessed by Shapiro-Wilk test. Freedom from event (CoA re-intervention) analysis was done through Kaplan-Meier method. Survival curves were generated to demonstrate re-intervention-free survival. A log-rank test was used to determine differences in the freedom from event distribution of independent groups. Binary logistic regression was used to analyse associations between patients' characteristics and identify independent predictors for re-coarctation intervention. A $p$-value of $<0.05$ was considered statistically significant for all tests. SPSS version 25 (IBM Corp., Armonk, New York) was used for all analyses.

\section{Results}

A total of 350 patients underwent surgical coarctation repair of the aorta in our centre from 1990 and 2016. After applying the inclusion criteria, 84 patients were included in the analysis. Patients' median age is $1(0.5-3.75)$ month. The majority of patients were infants $(48.8 \%)$ followed by neonates $(38.1 \%)$ at the age of diagnosis. Sixty-five patients (77.4\%) had juxtaductal CoA, 10 (11.9) patients had postductal CoA and the remaining $9(10.7 \%)$ patients had preductal type of CoA. All patients underwent surgical coarctation repair. Patients' characteristics are summarised in table 1.

\begin{tabular}{|l|c|}
\hline \multicolumn{1}{|c|}{ Characteristics } & Value \\
\hline Age at Diagnosis & $1.05(0.5,3.75)$ \\
\hline Age (months) & $32(38.1)$ \\
\hline Neonates (<1 month) & $41(48.8)$ \\
\hline Infant $(<1$ year) & $11(13.1)$ \\
\hline Children (<14 years) & \\
\hline Gender & $44(52.4)$ \\
\hline Male & $40(47.6)$ \\
\hline Female & $3(2.8,3)$ \\
\hline Weight & \\
\hline Premature/term & $7(8.3)$ \\
\hline Pre-term & $77(91.7)$ \\
\hline Term & $43(51.2)$ \\
\hline Prostin & \\
\hline Aortic Valve (AV) Type & $46(54.8)$ \\
\hline Bicuspid AV & $38(45.2)$ \\
\hline Tricuspid AV & $9(10.7)$ \\
\hline Coarctation Type & \\
\hline Preductal CoA & \\
\hline
\end{tabular}




\begin{tabular}{|l|c|}
\hline Juxtaductal CoA & $65(77.4)$ \\
\hline Postductal CoA & $10(11.9)$ \\
\hline Age at Surgery & \\
\hline Age (months) & $1.1(0.6,4)$ \\
\hline Neonates & $31(36.9)$ \\
\hline Infant & $38(45.2)$ \\
\hline Children & $15(17.9)$ \\
\hline Surgical Approach & \\
\hline Left thoracotomy & $78(92.9)$ \\
\hline Left anterolateral thoracotomy & $1(1.2)$ \\
\hline Left anterosternal thoracotomy & $4(4.8)$ \\
\hline Left posterolateral thoracotomy & $1(1.2)$ \\
\hline Type of Surgery & \\
\hline End to end anastomosis & $48(57.1)$ \\
\hline Extend to end anastomosis & $10(11.9)$ \\
\hline Subclavian flap & $26(31)$ \\
\hline
\end{tabular}

Table 1: Baseline and surgical characteristics of patients who underwent CoA repair.

Median age at surgery is $1.1(0.6,4)$ months. The majority of the patients were male $(52.4 \%)$ while median weight at time of repair was 3 (2.8 - 3) kilograms.

All 84 patients underwent surgical repair of CoA. The surgical approach for 78 (92.9\%) patients was through left thoracotomy, 4 (4.8\%) patients through left anterosternal thoracotomy, 1 (1.2\%) patient left anterolateral thoracotomy and left posterolateral for $1(1.2 \%)$ patient. The most common types of CoA repair for most patients $(48,57 \%)$ were end-to-end anastomosis, 26 (31\%) subclavian flap and extended end-to-end anastomosis for 10 (11.9\%) patients.

During a median follow-up of $121(21,174)$ months, need for reCoA intervention was $27.4 \%(n=23)$. Among patients who needed re-CoA intervention 11/23 (47.8\%) needed re-intervention within one year post-surgery. Most patients (21/23, 78.3\%) underwent re-intervention within the follow-up time of 21 months.

The following describes the data on the 84 patients that received re-intervention as summarised in table 2 .

The Kaplan-Meier re-CoA freedom from re-intervention was $168.4 \pm 10.3$ (mean \pm standard error) months. Freedom from re-

\begin{tabular}{|c|c|c|c|}
\hline \multirow[b]{2}{*}{ Characteristics } & \multicolumn{2}{|c|}{$\begin{array}{c}\text { Re-coarctation } \\
\text { Intervention }\end{array}$} & \multirow[b]{2}{*}{ p-value } \\
\hline & No & Yes & \\
\hline \multicolumn{4}{|l|}{ Gender } \\
\hline Female & $31(50.8)$ & $9(39.1)$ & \multirow[t]{2}{*}{0.339} \\
\hline Male & $30(49.2)$ & $14(60.9)$ & \\
\hline Pre-term & $4(6.6)$ & $3(13)$ & \multirow[t]{2}{*}{0.289} \\
\hline Term & $57(93.4)$ & $20(87)$ & \\
\hline \multicolumn{4}{|l|}{ Age Group at Diagnosis } \\
\hline Neonate & $22(36.1)$ & $10(43.5)$ & \multirow[t]{3}{*}{0.523} \\
\hline Infant & $32(52.5)$ & $9(39.1)$ & \\
\hline Child & $7(11.5)$ & $4(17.4)$ & \\
\hline \multicolumn{4}{|l|}{ Prostin } \\
\hline Yes $(n=43)$ & $29(47.5)$ & $14(60.9)$ & \multirow[t]{2}{*}{0.276} \\
\hline No $(n=41)$ & $32(52.5)$ & $9(39.1)$ & \\
\hline \multicolumn{4}{|l|}{ AV Valve } \\
\hline Bicuspid & $32(52.5)$ & $14(60.9)$ & \multirow[t]{2}{*}{0.490} \\
\hline Tricuspid & $29(47.5)$ & $9(39.1)$ & \\
\hline \multicolumn{4}{|l|}{ CoA Type } \\
\hline Juxtaductal & $45(73.8)$ & $20(87)$ & \multirow[t]{3}{*}{0.397} \\
\hline Preductal & $8(13.1)$ & $1(4.3)$ & \\
\hline Postductal & $8(13.1)$ & $2(8.7)$ & \\
\hline \multicolumn{4}{|l|}{ Age Group at Surgery } \\
\hline Neonate & $22(36.1)$ & $9(39.1)$ & \multirow[t]{3}{*}{0.752} \\
\hline Infant & $29(47.5)$ & $9(39.1)$ & \\
\hline Children & $10(16.4)$ & $5(21.7)$ & \\
\hline \multicolumn{4}{|l|}{ Surgical Approach } \\
\hline Left thoracotomy & $56(91.8)$ & $22(95.7)$ & \multirow[t]{4}{*}{0.851} \\
\hline Left anterolateral thoracotomy & $1(1.6)$ & 0 & \\
\hline Left anterosternal thoracotomy & $3(4.9)$ & $1(4.3)$ & \\
\hline Left posterolateral thoracotomy & $1(1.6)$ & 0 & \\
\hline \multicolumn{4}{|l|}{ Type of Surgery } \\
\hline End-to-end anastomosis & $33(54.1)$ & $15(65.2)$ & \multirow[t]{3}{*}{0.645} \\
\hline Extend end-to-end anastomosis & $8(13.1)$ & $2(8.7)$ & \\
\hline Subclavian flap & $20(32.8)$ & $6(26.1)$ & \\
\hline
\end{tabular}

Table 2: Characteristics of patients who had re-intervention.

CoA intervention at $1,3,5$, and 10 years was $98.8 \pm 1.2 \%, 78.1 \pm$ $4.6 \%, 76.8 \pm 4.7 \%$ and $71.1 \pm 5.1 \%$, respectively. Re-coarctationfree survival is shown in figure 1. 


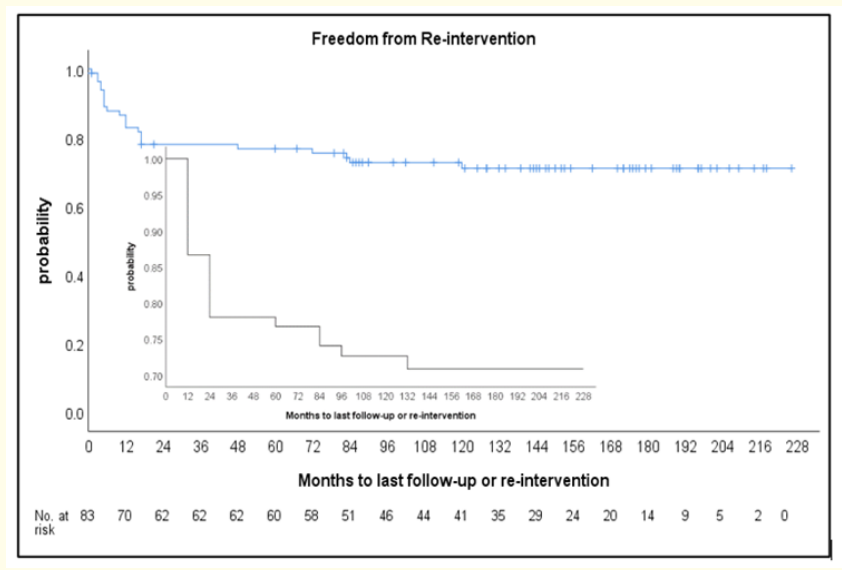

Figure 1: Freedom from re-intervention.v

A binary logistic regression was performed to ascertain the effects of the above entered independent variable on the likelihood that patients will need re-CoA intervention. Logistic regression model was not statistically significant $\left[\chi^{2}(8)=6.532, p=0.558\right]$. There were no risk factors identified in the model.

\section{Discussion}

The goal of our review of patients undergoing coarctation repair at Prince Sultan Cardiac Centre (PSCC) was to determine the risk factors for recoarctation and the clinical characteristics and anatomical parameters. Our review identified 350 patients who had CoA. After excluding those with other associated CHD, 84 patients had isolated CoA and received one of four different types of surgical repair. There is no consensus about which is the best technique for coarctation of aorta among the several described [11]; currently, the end-to end-anastomosis and extended end-to-end anastomosis techniques are the most used. We review multiple studies [13-15] such as Padalino., et al. which showed surgical repair by extended end-to-end anastomosis through a lateral thoracotomy and without cardiopulmonary bypass in paediatric patients is a safe and effective treatment to repair isolated CoA with or without hypoplastic aortic arch for both early and late outcomes. The incidence of late re-interventions is low and surgical re-operations are mostly related to associated CHD, where balloon dilation is most often an effective treatment. The majority of patients are clinically well in the long-term. Repair performed at an early age may reduce the incidence of arterial hypertension in the long-term [13]. This study found no effect of age, gender, prostin infusion and weight of the patient on recoarctation. Ame'lia Lehnert., et al. showed that preoperative medical management of CoA with the use of PGE1 in neonates has a significant impact on the risk of recoarctation. The modalities of PGE1 use should be reconsidered to obtain an adequate description of the aortic arch segments in order to optimally guide surgical repair [14]. Adamson [15] found that infants with a postoperative coarctation of aorta index of less than 0.7 warrant close outpatient follow-up to monitor for recurrent aortic arch obstruction and associated left ventricular dysfunction. Further prospective studies of the coarctation of aorta index are needed to validate it as a clinical tool in this patient population.

\section{Limitations}

This is an historical retrospective study with a relatively small sample. The sample was limited to a single centre and patients aged less than 14 years that had undergone surgical repair for CoA in the last three decades; there is a possibility of selection bias.

\section{Conclusion}

In our cohort, the incidence of recoarctation within two years of isolated coarctation of the aorta in patients aged less than 14 years is $27.4 \%$. We were unable to identify any risk factors for recoarctation, further larger prospective studies would be essential to identify possible risk factors of reoarctation in children with isolated coarctation of aorta.

\section{Conflict of Interest}

The authors declare that no conflict of interest exists.

\section{Bibliography}

1. Crafoord C and Nylin G. "Congenital coarctation of the aorta and its surgical treatment". The Journal of Thoracic Surgery 14 (1945): 347-361.

2. Hoffman JIE and Kaplan S. "The incidence of congenital heart disease". Journal of the American College of Cardiology 39.12 (2002): 1890-1900.

3. Gross RE. "Surgical correction of coarctation of the aorta". Surgery 18 (1945): 673.

4. Vosschulte K. "Surgical correction of the aorta by an "isthmus plastic" operation"'. Thorax 16 (1961): 338. 
5. Waldhausen JA and Nahrwold DL. "Repair of coarctation of the aorta with a subclavian flap". The Journal of Thoracic and Cardiovascular Surgery 51 (1966): 532.

6. Amato JJ., et al. "Role of extended aortoplasty related to the definition of coarctation of the aorta". The Annals of Thoracic Surgery 199152 (1991): 615-620.

7. Quaegebeur JM., et al. "Outcomes in seriously ill neonates with coarctation of the aorta: a multi-institutional study". The Journal of Thoracic and Cardiovascular Surgery.

8. Kappetein AP., et al. "More than thirty-five years of coarctation repair: An unexpected high relapse rate". The Journal of Thoracic and Cardiovascular Surgery 107 (1994): 87-95.

9. Wright GE., et al. "Extended resection and end-to-end anastomosis for aortic coarctation in infants: results of a tailored surgical approach". The Annals of Thoracic Surgery 80.4 (2005): 1453-1459.

10. Burch PT., et al. "Coarctation repair in neonates and young infants: is small size or low weight still a risk factor?" The Journal of Thoracic and Cardiovascular Surgery 138.3 (2009): 547-552.

11. Ungerleider RM., et al. "Contemporary patterns of surgery and outcomes for aortic coarctation: an analysis of the Society of Thoracic Surgeons Congenital Heart Surgery Database". The Journal of Thoracic and Cardiovascular Surgery 145 (2013): 150-157.

12. Walhout RJ., et al. "Comparison of polytetrafluoroethylene patch aortoplasty and end-to-end anastomosis for coarctation of the aorta". The Journal of Thoracic and Cardiovascular Surgery 126 (2003): 521-528.

13. Massimo A Padalino., et al. "Surgical repair of aortic coarctation in pediatric age: A single center two decades experience". WILEY Cardiac Surgery Journal (2019).

14. Ame'lia Lehnert., et al. "Risk factors of mortality and recoarctation after coarctation repair in infancy". Interactive Cardio Vascular and Thoracic Surgery (2019) 1-7.

15. Gregory Adamson., et al. "Coarctation Index Predicts Recurrent Aortic Arch Obstruction Following Surgical Repair of Coarctation of the Aorta in Infants". Pediatric Cardiology (2017).

\section{Assets from publication with us}

- Prompt Acknowledgement after receiving the article

- Thorough Double blinded peer review

- Rapid Publication

- Issue of Publication Certificate

- High visibility of your Published work

Website: www.actascientific.com/

Submit Article: www.actascientific.com/submission.php

Email us: editor@actascientific.com

Contact us: +919182824667 